Monografico: El reto del ciclismo urbano, texto 8: 129-146.

\title{
POBRES, DEPORTISTAS Y ECOLOGISTAS. Paradojas, estereotipos y afectos en el ciclismo urbano, un análisis desde las corporeidades
}

\author{
Mario JORDI SÁNCHEZ \\ Universidad Pablo de Olavide (España) \\ amjordi@upo.es
}

\begin{abstract}
POORS, ATHLETES AND ECOLOGISTS. Paradoxes, stereotypes and affects in urban
\end{abstract} cycling: an analysis from corporealities

Resumen: Más allá de vincularse exclusivamente con una reacción ambientalista planteada ante la hegemonía del transporte motorizado, el ejercicio del ciclismo urbano puede presentar muchas y variadas lecturas. En esta aportación se aborda este fenómeno desde el análisis antropológico del cuerpo en movimiento, constatando la diversificación de usos corporales, afectos e imágenes que comporta la presencia de ciclistas en la ciudad, paralela a la persistencia de estereotipos y a los ejercicios de pugna por el espacio y de control de la movilidad. En especial, subrayaremos la presencia de algunos modelos de cuerpo concretos como referentes de los discursos y prácticas de los usuarios y a la vez como elementos clave en los escenarios de promoción de la bicicleta desde un enfoque lúdico-deportivo, generando un juego de dualidades que presenta múltiples trampas, como las que se establecen entre salud individual y colectiva, entre deporte y transporte y entre ocio y trabajo.

Abstract: Beyond exclusively linked with an environmental reaction brought before the hegemony of motorized transport, urban cycling can have many and varied readings. This contribution is approached from the anthropological analysis of the moving body, noting the diversification of personal uses, affects and images that involves the presence of cyclists in the city, parallel to the persistence of stereotypes and struggles for space and mobility control. In particular, we stress some models of body as references of discourses and practices of bike users and also as key elements in the stage of promotion of cycling from a recreational-sports approach, generating a set of dualities that has many contradictions, as established between individual and collective health, between sport and transport and between leisure and work.

Palabras clave: Bicicleta, Ciclismo urbano. Cuerpo. Afectos. Estereotipos

Bycicle, Urban Cycling. Body. Affect. Stereotypes 


\section{La reconquista de la ciudad en bicicleta: entre la idealización y la subcultura, entre la búsqueda y la huida}

¿Qué elogios pueden hacerse a la bicicleta que no se hayan hecho ya? Por si no bastara con constatar la impresión que nos deja el semblante relajado y sonriente de la persona en bicicleta con la que nos hemos cruzado, los discursos predominantes que nos hablan sobre este objeto apuntan a una indiscutible idealización. De su asociación con el juego, la evasión, la independencia, la movilidad o la naturaleza hablan numerosos relatos en prosa y no pocos en poesía ${ }^{1}$. Su vinculación con la salud, el deporte y el bienestar llenan los tratados sobre movilidad sostenible, mientras un gran número de aportes científicos o literarios, desde el ensayo social a la bibliografía específica sobre el tema refieren su eficiencia técnica, por encima de cualquier vehículo, así como su carácter liberador y emancipador (véase por ejemplo: Augé, 2009. Dekoster y Schollaert, 1999. Illich, 1985. Pucher y Buehler, 2012).

En dicha literatura, buena parte del habitual elogio de la bicicleta se centra en su comparación con otro medio de transporte (el automóvil) frente al que, según se argumenta, se evidencia una significativa revitalización de los sentidos, un aumento de las posibilidades de activación de la experiencia corporal y una efervescencia emocional, en definitiva, que lleva a fortalecer las conexiones con los demás y con uno mismo, lo que se traduciría en un progreso firme de la autoestima. En una sociedad de intenso control de las emociones, lo que implica control de los cuerpos (Elías y Dunning, 1992: 65), la bicicleta, en su reencuentro con el esfuerzo, con los desafíos del clima o con los avatares del camino, procura no solo una explosión sensorial, sino una amplia sensación de libertad de movimientos (Pucher y Buehler, 2012), arrojando al cuerpo a ese columpio de la dualidad dolor-placer tan intrínsecamente ciclista (Krabbe, 2010). Un nuevo sentido de liberación toma lugar, posibilitando ampliar las necesidades de movilidad de una sociedad sedentaria, rescatando nuestro nomadismo más íntimo de su letargo inmovilista, escapando del enclaustramiento y la confinación domiciliarios (Maffesoli, 2004:14).

En el ámbito urbano, se argumenta, la bicicleta ablanda, personaliza la ciudad con su humanismo contrastivo frente a la agresividad y omnipresencia del coche (Urry, 2004). Desde un punto de vista racionalista, el pedalear, con su aplastante eficiencia, subraya el sinsentido de los modos de desplazamiento vinculados al consumo de recursos finitos (Horton, 2006). Discute además la propia configuración espacial de la ciudad, poniendo en evidencia su desarrollo urbanístico y contribuyendo a contrarrestar esa tendencia centrífuga por la cual se expulsa no solo a los ciudadanos de su ciudad, sino a esta de sí misma (Jacobs 2011: 156).

Sin embargo, y junto a todo lo anterior, la bicicleta podría entenderse también como producto de las necesidades de huida que las sociedades occidentales presentan: de buscar continuamente escaparse (esta vez pedaleando) de sí misma, de sus contradicciones y de sus excesos, en una persecución sin fin de la autoestima (Luhmann, 1998:96). La bicicleta que en nuestras ciudades ahora se idealiza no es, de forma mayoritaria, el vehículo que facilita la movilidad en situaciones de miseria, o la forma de movilidad impuesta por regímenes totalitarios. Es la bicicleta de contadas ciudades del mundo, donde se plantea como una "nueva opción" ante la hegemonía del transporte motorizado y los miedos que este genera (Horton, 2012). Sigue así la estela de los casos más notorios del centro y norte de Europa, pero se nutre del sentido dominante que la bicicleta adquiere culturalmente en cada contexto. Como apuntan Horton y Parkin (2012: 308) en el caso español, como en otros países del entorno (Francia e Italia, por ejemplo), los referentes simbólicos a los que la bicicleta se asocia no son los del transporte cotidiano. Salvo la memoria que mantiene aún la generación que vivió

1 Una interesante selección es la que realizan Francisco Vélez Nieto y Fran Nuño en el volumen titulado "Poetas en bicicleta" (2007). Sevilla: Nuño editorial. 
los años cuarenta y cincuenta del siglo pasado, el presente de la bicicleta como transporte se fundamenta, de forma dominante, en un objeto en el que priman su calidad de juguete, de artículo deportivo y de instrumento de evasión que, dada su implantación cuantitativa, de forma aún muy minoritaria planta cara a la dictadura del transporte privado motorizado a escala ideológica, social, urbanística, política y económica.

En este sentido, en la medida en que la práctica del ciclismo como transporte se ha venido desarrollando en escenarios tan hostiles para pedalear como las ciudades actuales, dicha práctica se ha ido impregnando de un halo de excepcionalidad que redunda en su concepción social en términos de "anormalidad". Como apuntan Horton y Parkin (2012: 306) el resultado no puede ser otro que el de convertir a la práctica ciclista en una actividad subcultural, hasta el punto de que la desaparición de un ciclismo "ordinario" o "cotidiano" (en detrimento de un ciclismo "parcial" o "excepcional") se convierte a la vez en causa y consecuencia de un hecho común y extendido: pedalear en las ciudades se convierte, por lo general, en una actividad difícil y peligrosa (Horton, 2012).

Bajo el signo de una opresión común ejercida desde la supremacía del coche, las identidades ciclistas se han ido desarrollando de un modo que podría calificarse como reactivo o contra-cultural, configurándose así a modo de "identidades antagonistas" (Horton y Parkin, 2012: 307). Se comprende así que la "cultura ciclista" cobre sentido básicamente en términos de minoría que se evidencia con respecto a una mayoría de formas de desplazamiento. La importancia de la "identidad ciclista" (en su aplastante heterogeneidad, que prácticamente la diluye desde su constitución) se asocia a un marco reactivo. Procede de una vivencia estigmática: se admite, incluso se abraza, porque ofrece solidaridad y protección, como advierte P. Cox: "garantiza el no considerarse individuos aislados o desviados, incluso puede servir de trampolín para ser visto como parte de una minoría significativa" (Cox, 2015: 21). Este autor se apoya en la idea de Gelder (2007) de subcultura, en términos de posición de cierta marginalidad o "no-normatividad", más que en la idea de culturas o identidades, fundamentándose en el devenir histórico por el que, después de la segunda mitad del s. XX en Europa el transporte ciclista quedó relegado con respecto al transporte motorizado privado, de ahí tal carácter y posición subcultural.

Sin embargo, en un contexto de declive mundial del transporte ciclista, en los últimos años, diversas experiencias en algunas grandes ciudades españolas, coetáneas con otros lugares en el mundo plantean una excepción a esta regla (Horton y Jones, 2015) y dan cuenta de un proceso de visibilización de la bicicleta que algunos interpretan como los primeros pasos, aún incipientes pero necesarios, para cimentar un cambio en los modos de desplazamiento dominantes, si no en términos de "revolución ciclista" (Horton y Parkin, 2012), al menos en un giro hacia la normalización (Aldred y otros, 2016). En las líneas que siguen nos interrogamos en parte sobre el alcance de estos procesos en nuestras ciudades, subrayando la existencia de una serie de paradojas y contradicciones que emergen a la luz del análisis etnográfico de los discursos y prácticas de ciclistas en Andalucía desde el enfoque de las corporeidades y que llevan a la necesidad de revisar las nociones de salud, ocio, deporte y ambientalismo, partiendo del análisis de los afectos y estereotipos.

\section{Cuerpos que (se) miran con afecto: la construcción del estereotipo ciclista}

La sociología clásica nos dice que es el sentido de la vista el que gobierna la ciudad. Desde la supremacía de la mirada, los análisis de G. Simmel (1921:369) advierten una "ciudad nerviosa" que obliga a acelerar los contactos visuales para informar y ser informados de los demás, centrándose en la información que los rostros se muestran entre sí. Con respecto al conjunto de vehículos que pueden circular por la ciudad, en su calidad de objeto corporeizado, la bicicleta ejerce como "pedestal" para las miradas, por su relativa rareza como medio de transporte y por su contraposición al hermetismo de vehículos-cápsula, descorporeizados 
y despersonificadores (Urry, 2004). También mirar desde la bicicleta, desde la fugacidad del encuentro en movimiento, tiene mucho de vivencia animada, tipo road-moving. Cuerpos ciclistas que visualizan fugazmente sus caras, expuestos sus colores y su juego de curvas móviles y que rápidamente exhiben la espalda, el trasero o incluso muestran el sudor, configuraciones corporales estas últimas que la sociedad encuentra por lo general menos dignas y respetables. Respetabilidad corporal aún más en juego en aquellos momentos y situaciones sociales en las que el ascenso en la jerarquía social o el desempeño de algunos roles deviene en el ejercicio de cierta descorporeización, produciéndose el control de los gestos, de fluidos y excreciones (Douglas, 1978: 97).

Desde otro enfoque, estos cuerpos expuestos suman un conjunto interpelador: la imagen de la persona en bicicleta apela a los sentidos, pero también a los sentimientos, generando afectos, suscitando emoción. Entendemos por ello que la práctica ciclista en las ciudades puede leerse como una expresión de los afectos y de las emociones. Expresiones corporeizadas de difícil aprehensión, como refiere Spinney (2007: 29-30) porque nuestra percepción del entorno está conformada por los objetivos, las habilidades y la tecnología de que disponemos, por lo que en consecuencia está constreñida por el limitado vocabulario de que disponemos, estrechamente vinculado al vocabulario visual. En todo caso, podemos advertir que buena parte de esta asociación de la bicicleta con los afectos encuentra su explicación en que los cuerpos en bicicleta son, esencialmente, cuerpos en movimiento. Entendemos aquí los afectos en la línea de Massumi (2002:61), no solo como capacidad de afectar y apertura a sentirse afectados, asociada a mecanismos propioceptivos, y por tanto, no siempre conscientes (Clough, 2008: 1), sino también en su asociación con la biopolítica, en la posibilidad de producir "efectos ideológicos por medios no ideológicos" (Leys, 2011: 435). Esta asociación biopolítica significa que la práctica ciclista en las grandes ciudades se plantea como una forma de expresión corporeizada que revela, a través de la exposición de imágenes de cuerpos en movimiento, buena parte de las fracturas, contradicciones y tensiones urbanas. Así, en la línea que argumenta J. Butler, "el cuerpo no se configura como una superficie disponible que espera significación, sino como un conjunto de límites individuales y sociales que permanecen y adquieren significado políticamente" (2001: 99). Huimos así de una visión estatista de los fenómenos sociales que parte de una concepción del cuerpo como mero objeto, conviniendo con M. Featherstone (2010: 208) en que el cuerpo no puede ser objetivado, pues "no es simplemente un objeto ni un "sujeto-objeto", no es una cosa con una imagen fija o determinada. No es sólo algo que ocupa un único espacio sin fisuras, sino que participa en los movimientos a través de una diversidad de espacios discontinuos.". Sin embargo, en una modernidad atiborrada de imágenes que tienen por motivo el cuerpo, el ejercicio de la contemplación, como sugiere Velasco (2010:30), hace que "ya no son meras imágenes sino poses, no son meros cuerpos sino cuerpos expuestos". Pero tales exposiciones no son neutras, sino que presentan una potencial polisemia, una carga de sentido que es activado, potenciado o silenciado en circunstancias y contextos diversos. En este sentido, el estudio de los estereotipos, más allá de su análisis como simplificación de lo real, puede entenderse como causa y a la vez como consecuencia de la atribución de cargas afectivas a los cuerpos de modo diferencial y convenido socialmente. Los estereotipos nos informan grosso modo de procesos sociales, pues resumen tendencias y fracturas sociales, pero también las reducen, en una suerte de para-simplificación, en la medida en que parten de construcciones de sentido autoexplicadas, dualistas y potencialmente normalizantes. A continuación analizamos algunos de estos estereotipos, a la luz de la experiencia etnográfica en las grandes ciudades andaluzas, en la producción de cuatro frentes de estereotipos ciclistas: cuerpos atléticos, cuerpos ociosos y cuerpos contestatarios. 


\section{Cuerpos atléticos: entre el deporte y el transporte}

En uno de nuestros foros de participación organizados con ciclistas y ciudadanía en general, nos llamó la atención la opinión de un ciclista que se decía a la vez usuario de este medio como modo cotidiano de transporte y también como forma de hacer deporte esporádicamente de forma intensiva. En una bicifestación en Cádiz decía haberse enfrentado dialécticamente con algunos activistas cuando estos empezaron a lanzar repetidamente el lema "no es un deporte, es un transporte". Ricardo (nombre ficticio) se mostraba molesto y a la vez dolido por la forma en que se era excluido simbólicamente de unas reivindicaciones que entendía que le afectaban, quejándose de que este tipo de planteamientos no le hacía ningún favor al colectivo ciclista en general.

Al margen de que alguien pueda considerar que Ricardo tal vez pueda ser una "rara avis" en el núcleo duro del activismo pro-bicicleta, la referida anécdota nos informa de una de las principales tensiones que se elaboran con respecto a la producción de sentido sobre la práctica ciclista, y que tiene que ver con una de las identificaciones dominantes de la bicicleta, ya apuntada al principio, es decir, la bicicleta como medio para realizar una actividad físico-deportiva, identificación esta que remite claramente a la primacía del imaginario del cuerpo atlético en nuestra sociedad.

En nuestro trabajo de campo, los testimonios recogidos en diferentes ámbitos apuntan a la consolidación de este imaginario resumido en sentencias del tipo: "la población ciclista es deportista, le atrae el ejercicio físico y, por lo tanto, le gusta estar en forma". Se trata de personas "preocupadas por la salud, por el deporte, que en nuestra sociedad es equivalente a decir que se preocupan por su cuerpo". En estas enunciaciones ya se advierte la incorporación de la bicicleta, de forma explícita o implícita, en proyectos personalizados de transformación corporal. Proyectos en los que es el objeto de consumo (la bicicleta) el que incorpora en buena medida el sentido a la acción deportiva, por lo que su consumo ya es parte consustancial al acto deportivo. En palabras de Baudrillard: "De la higiene al maquillaje, pasando por el bronceado, el deporte y las múltiples «liberaciones» de la moda, el descubrimiento del cuerpo pasa primero por los objetos. Hasta parece que la única pulsión verdaderamente liberada es la pulsión de compra..." (2009:163). La bicicleta es a la vez el objeto de consumo como fetiche y la prótesis que garantiza el ejercicio deportivo. Lo más relevante en este caso es la necesidad de tener presente aquellas prácticas que asumen una de las principales lógicas físico-deportivas (la transformación corporal) pese a desenvolverse en escenarios "de transporte", como se resume en los siguientes testimonios: "Mira, no tengo tiempo de ir al gimnasio, pero como todos los días me voy desplazando y hago no sé cuántos kilómetros en bicicleta, pues ya estoy haciendo ejercicio" (Usuario de la bicicleta, Granada). "No estás pagando un gimnasio para hacer ese ejercicio y estás paseando por tu ciudad" (Usuario de la bicicleta, Sevilla).

Pensamos que es comprensible, por ubicarse dentro de lo que se considera comúnmente en el terreno de la intimidad que los testimonios más explícitos sobre la asociación entre uso de la bicicleta y transformación corporal (con intenciones como "eliminar cartucheras", "aligerar la barriguita", "hacer desaparecer la celulitis"...) no sean fácilmente referidos en los discursos de nuestras entrevistas más formales, en comparación con las alusiones a la salud o la utilidad, lo cual no quita que nos hayamos encontrado con ellos en contextos de mayor complicidad, empatía o confianza. De otro lado, otra evidencia recurrente de que la bicicleta se usa como actividad física corporalmente transformadora es la medida del rendimiento físico propio. Como advierten Vigarello y Holt (2005: 295), desde que el deporte moderno se instituye en el centro de las prácticas, emerge la racionalización del rendimiento del cuerpo como uno de sus primeros y más patentes sus resultados, a través de la medida, del récord o de la marca. Aquí, la "vuelta" a tomar conciencia del cuerpo se plantea en términos de resultados conseguidos, bien cuantificados (kilos, centímetros, calorías...) bien 
medidos por las referencias que el espejo devuelve acerca del contorno, la firmeza muscular o la disminución de grasas localizadas. Como se ilustra en los siguientes testimonios:

"Ahora me gusta coger la bici, para moverme un poquillo y tal. Yo estoy casi todo el rato sentado trabajando. Entonces, aunque sean diez minutos de ida y vuelta con la bici... Pero también es una forma que te das cuenta de lo mal que estás físicamente, y lo destrozado que estás.., iy lo mayor que te estás haciendo! [...] Pero vamos, quitando las primeras semanas, que notaba un poco las piernas, que luego temblabas cuando llegabas a casa... ahora tampoco es ningún desgaste." (Usuario de la bicicleta, Córdoba).

"Es un deporte en el que siempre mejoras, si coges un hábito mejoras muchísimo. Y como siempre vas con gente, puedes ver que antes ibas detrás y ahora vas con no sé cuánta gente detrás, y te mides con ellos... Porque en el fondo, aunque no queramos competir, todos y todas nos damos cuenta de eso. Luego es un deporte muy aeróbico, que quema mucha grasa, tu cuerpo cambia completamente y a todos nos gusta vernos mejor frente al espejo, y aunque ya de por sí las endorfinas y todo lo que se genera te pega el subidón, es que además tu autoestima aumenta siempre" (Usuario de la bicicleta, Granada).

Aunque los cuerpos atléticos son de rara presencia (Vigarello y Holt, 2005), su imaginario es omnipresente, y se convierten en la norma a seguir, dentro de una suerte de "ética de la estética" (Maffesoli, 2007). Se trata de cuerpos que se autoconciben como "liberados" pero en realidad se encuentran atados a un modelo difícil, cuando no imposible, de alcanzar. Lo central en ellas es la renuncia, el control disciplinario sobre el propio cuerpo, en palabras de Foucault (1983: 126). Pero en el camino para lograrlo también está el goce, por lo que paralelo a la lógica ascética cierto marchamo hedonista impregna estas prácticas (Jordi, 2014). También cierta docilidad egocéntrica, de un narcisismo que podría entenderse como carente de trascendencia, pero que en realidad tiende a la "celebración del cuerpo" (Lipovestsky, 2000:52), a sustituir las creencias por las emociones, dentro de los límites que la sociedad y sus ataduras le permite.

En todo caso, nos ubicamos dentro del ciclismo "de transporte" y aquí las lógicas ascéticas y narcisistas se presentan, al menos en los discursos, con menor contundencia. De hecho, tales lógicas subsisten con razonamientos discursivos que contrastan con el estereotipo del ciclista como alguien indiscutiblemente "atlético", preocupado por el ejercicio físico. Es el caso de cierto perfil de usuarios que presentan hábitos consolidados de uso de la bicicleta y que se mueven en entornos que no les suponen excesivos obstáculos o impedimentos para la circulación en bicicleta, y para los que moverse con este medio significa, sencillamente, hacer menos esfuerzo:

"Prefiero la bici a caminar. Es muchísimo más práctico, tardas mucho menos tiempo, no tengo que cargar la compra... Es más cómodo. A veces la gente me dice: ¡Ah, tú vas en bici, haces ejercicio...! Pero para mí es como que me resulta más duro caminar" (Usuaria de bicicleta, jubilada, 65 años, Granada).

De este modo, en la visualización de las prácticas y en el análisis de los discursos se advierten también solapamientos en las lógicas deportivas y de transporte que desaniman desde el principio, como ya avisábamos, la elaboración de rígidas taxonomías. Más bien podríamos hablar aquí de deporte, o de actividades físico-deportivas "explícitas" o "implícitas", según que sean o no enunciadas y admitidas socialmente como tales (Jordi, 2016b: 183). Algunos escenarios de los referidos solapamientos entre deporte y transporte, encontrados en nuestro trabajo de campo son los siguientes: 
- Usuarios/as de la bicicleta que insisten en "no hacer deporte alguno", pero que se desplazan por este medio al lugar de trabajo o estudio, recorriendo diariamente decenas de kilómetros.

- La observación frecuente de prácticas ciclistas "deportivas" como las relacionadas con la competitividad, ubicadas en escenarios urbanos comúnmente considerados "de transporte", y concretados en "piques" entre usuarios/as de la bicicleta de distinta edad, sexo, condición física, etc. mediante aceleraciones, pasos elevados, etc.

- Las prácticas "deportivas" calificadas también como "tendencias urbanas" (la práctica del bmx, por ejemplo) vinculadas comúnmente a la sociabilidad, el microgrupo y el afán estético, pero que realmente son mucho más que una subcultura. Podrían entenderse también como modos alternativos de expresar y redibujar la propia ciudad, dentro de una lógica "traceur", como ocurre con el parkour y otras tendencias sociodeportivas actuales.

- Las prácticas "deportistas" de miles de usuarios que dicen "hacer deporte" (usuarios/as de la bicicleta de montaña, por ejemplo) y en los que la importancia de la sociabilidad, del escape de la cotidianeidad y de las actividades de comensalismo tienen un peso simbólico y real superior a lo que estricta y comúnmente se concibe como "deportivo". En las salidas al campo de estos usuarios, la "experiencia deportiva" suele consistir en un paseo dominical de ida y vuelta a un bar de pueblo en el que se da cuenta de desayunos largos y copiosos. En otros casos, una vez de vuelta, el tercer tiempo impone unas cervezas que, se conviene, "habiendo sudado sientan mejor".

- Para muchos otros, hacer deporte es usar objetos deportivos. Entre los que se lo pueden permitir, no falta quienes exhiben bicicletas pensadas para un uso deportivo profesional, junto al cada vez más tecnificado y complejo atrezzo que le acompaña, como rutómetros, pulsómetros, potenciómetros, y que remarcan la idea de que es la medida la que hace al deporte y no al revés. En todo caso, tales usos también se acompasan a un ritmo de paseo, involucradas en otras lógicas de prestigio dentro del microgrupo, como marcador de clase, etc.

- En general, en conexión con lo anterior, el protagonismo de los "ciclistas de lycra" (o si se prefiere, los MAMIL, acrónimo de "Middle-Age Man In Lycra" como son referidos por Aldred y otros, 2015:14), en sus paseos dentro de la ciudad, les acerca al "ideal deportivo" aunque en la práctica el ejercicio realizado se resuma en circular tranquilamente por una zona verde para despejarse de las tensiones y pesares de la jornada laboral, de los estudios o de la vida en general. Son "los ciclistas que sudan", y es el sudor deportivo, un sudor sin duda más admitido socialmente, el que marca la distancia entre el deporte y el transporte. La actividad es deportiva porque ella "se suda", independientemente, claro está, de que sea un sudor inventado, presupuesto por la apariencia corporal.

La construcción social del deporte, como la del transporte, obedece a las diferentes enunciaciones y prácticas que, contextualmente se elaboran por los individuos y colectivos. De este modo, lo que define al acto deportivo puede ser desde un acto de consumo, pasando por una actitud, una vestimenta o el uso de un objeto sofisticado. Sin embargo, y dejando de lado el carácter presumida y estereotipadamente "apolítico" del ciclista-deportista (para ampliar esta cuestión en el caso andaluz, véase: Jordi, 2016b: 197-200), si hubiera que destacar un ámbito social en el que algunos agentes sociales se afanan en diferenciar lo deportivo de lo no deportivo, ese es el de la praxis política y las elaboraciones discursivas que se le asocian. Y no precisamente, como decíamos al principio, porque algunos colectivos de activistas planten estrategias de diferenciación, sino también, y sobre todo, porque desde la planificación de las ciudades a las políticas de promoción de la bicicleta, el argumento de ocio-deportivo sigue ocupando un papel predominante.

El caso de Sevilla, y la posterior implantación del llamado Plan Andaluz de la Bicicleta a partir de 2013, marcan un precedente en lo que tiene que ver con políticas de promoción 
del uso de la bicicleta como medio de transporte (Márques y otros, 2015:31). Pero en otros muchos otros ámbitos, buena parte de los eventos y actos institucionales relacionados con la bicicleta se han orientado demasiado recurrentemente a lo deportivo, a lo lúdico (Del Río y Coca, 2016: 64), apoyándose en las ideas dominantes de "salud" y de ejercicio físico, pero a la vez sin incidir de forma comprometida en su dimensión utilitaria y en su potencial para transformar el actual modelo de movilidad. Se sitúan aquí prácticas políticas recurrentes, cuestionadas por los movimientos pro-bici, como el aliento excesivamente concentrado en la celebración de grandes actos deportivos ciclistas "porque suponen promoción de la bicicleta", a la vez que se construyen kilómetros de infraestructuras ciclistas ubicadas lejos de nodos de interés (centros de trabajo y estudio, nodos de transporte, etc) pero cerca de zonas verdes o extrarradios, escasamente articuladas entre sí y, en consecuencia, infrautilizadas (Martín y Gálvez, 2016: 49). El efecto perverso que todo esto procura, según los colectivos pro-bici andaluces consultados, supone que no tenga consecuencias significativas en la modificación de los hábitos de movilidad en la ciudad y que sean los mismos ciclistas los que reniegan de su uso. Esta línea de intervención, que podríamos llamar "ocio-céntrica" encuentra un ejemplo claro en la proliferación de las llamadas "rondas del colesterol" presentes en algunas ciudades y pueblos. De trazado en términos de "circunvalación urbana", plantean un uso estéril, poniendo aquí de acuerdo las lógicas de "deporte" y "transporte", bien porque "no conectan con nada ni llevan a ningún lado", como refieren los usuarios, bien sencillamente porque transcurren por lugares apartados e inhóspitos: pocos se animan a un paseo por el extrarradio de la ciudad. Aquellos a los que en la consulta le prescribieron largos paseos diarios prefieren elegir otras zonas más atractivas, por lo que no se confirma con el uso su acepción popular. Este tipo de empeños desde las infraestructuras se combina, tal y como denuncian algunos colectivos pro-bici, con una resistencia a la construcción de carriles-bici dentro del trazado urbano dentro de una red articulada y coherente, que conduzca a los citados nodos de interés. En general, se trata de un tipo de políticas que ahondan en una pretendida polarización deporte-transporte, pero que sobre todo terminan menospreciando la importancia de la bicicleta como medio cotidiano, al tiempo que no contempla las necesidades reales de las prácticas más orientadas al ocio y al esparcimiento. Se pretende así igualar kilómetros construidos de carril-bici con apuestas reales y efectivas por la mejora del medio ambiente de la ciudad, conjugándose con sobreactuaciones discursivas en términos de "apuestas por la salud y el deporte" y, sobre todo, con la ausencia de medidas que desincentiven el uso de otros modelos de transporte menos sostenibles ambientalmente. En definitiva, el deporte se convierte en "auténtico referente de pureza, lealtad y amistad" (Caillat, 1999), en el argumento central que "blanquea" políticas continuistas e inmovilistas con respecto a los graves desafíos que las ciudades presentan en términos de movilidad y sostenibilidad. En este sentido, la alusión al deporte funciona, como advierte Sánchez Martín a modo de "discurso redundante que reduce la complejidad de las narrativas sobre lo social" (2011: 478), posibilitando así la producción selectiva de formas psíquicas y sociales, y al mismo tiempo que genera cohesión, funciona como un código que resume y absorbe las contradicciones societarias.

\section{Cuerpos ociosos: entre la obligación y el tiempo libre}

El hecho de que la práctica ciclista de la que estamos hablando se sustente sobre argumentos relativos al ocio y al tiempo libre genera una serie de contradicciones con nuevas prácticas que integran aspectos socioproductivos dentro del pedalear. En nuestras observaciones y entrevistas percibimos que, con los efectos de la crisis económica, en las ciudades andaluzas de mayor proliferación ciclista (Sevilla, Córdoba, Granada, Málaga y Cádiz), se advierte un claro aumento de la presencia de oficios que se apoyan en el uso de la bicicleta. El cambio no es solo cuantitativo sino también cualitativo: el argumento común es 
una mayor diversidad en los oficios ciclistas en los cuales la bicicleta cobra un renovado protagonismo. Este fenómeno es relativamente novedoso: salvo las personas que superan ampliamente la frontera de los 60 años, la experiencia ciclista raramente ha estado vinculada con un desempeño profesional, o con oficios específicos que hayan dejado un hábito corporal o una vinculación simbólica de la bicicleta con lo productivo. Una evidencia que se complementa con un estereotipo persistente por el que se considera al ciclista como alguien "pobre", "ocioso", sin recursos para poder adquirir un vehículo motorizado, incluyendo aquí a personas de otros orígenes etno-nacionales, a las que socialmente se les pueda atribuir tal condición depauperada, o a jóvenes a los que se les imagina en la misma condición.

Desde diferentes enfoques, se ha venido estudiando la relación entre los cuerpos y el ejercicio de oficios y profesiones, centrándose en la variable clase social las aproximaciones más recurrentes. Suele así encontrarse en las clases populares (Boltanski, 1971: 222-223) una relación más instrumental con el cuerpo, concretada en el ejercicio de la fuerza física y en desempeño del trabajo manual, en contraste con el trabajo intelectual o la ocupación en empeños más abstractos y sofisticados, vinculados a las clases acomodadas. En esta línea, P. Bourdieu asocia estas divisiones societarias a la circulación de un "capital cultural incorporado", vinculado con las posiciones de clase que se espera que cubran los sujetos y sus cuerpos (1990:210).

En nuestro trabajo etnográfico encontramos que, en términos de clase, el uso de la bicicleta desde un prisma socioproductivo se vincula, en primera instancia, con ocupaciones en las que el desempeño físico y la exposición al entorno son fundamentales. Es el caso de una amplia gama de nuevos y viejos oficios que se han ido readaptando a los nuevos tiempos, en cuyo origen están intereses, necesidades y expectativas diversas. La emergencia de estos oficios en nuestras ciudades es de relativa novedad y, como decíamos, podría argumentarse que tiene una raíz "postmoderna". Es decir, se trata de oficios tradicionales recuperados o resignificados y que usan la bicicleta para sus desplazamientos o como herramienta de trabajo, entre los que encontramos: bicimensajeros, carteros, personal de limpieza pública, publicistas, afiladores, repartidores de pan y periódicos, mecánicos ambulantes, limpiacristales, personal de seguridad, pintores, jornaleros, vendedores ambulantes, traperos, chatarreros... En todos estos casos, son argumentos comunes: el uso de la bicicleta como herramienta básica, el protagonismo del desempeño físico, el ejercicio de la manualidad, la continua movilidad, la exposición al medio, la lucha con el tráfico rodado y el predominio de la presencia masculina. Estos ejemplos basculan entre empleos informalizados, con el uso de bicicletas propias de escaso coste y adaptadas al desempeño del oficio, y aquellos trabajos más formalizados en los que es la empresa o la entidad que contrata la que proporciona bicicleta, imagen productiva, herramientas e indumentaria. Sin duda, estos últimos casos procuran una imagen de mayor respetabilidad, en cuyo extremo se encontraría el personal de seguridad y los agentes de la policía local.

El denominador común, más presente en aquellos oficios que se han pasado desde el empleo de vehículos motorizados a las bicicletas, es el de la recorporeización, relacionada con el rescate de sensaciones físicas y emocionales que conlleva circular en bicicleta. Así, a las implicaciones en términos logísticos, como la mayor eficiencia en trayectos cortos y medios, la mayor maniobrabilidad o los menores contratiempos por el aparcamiento se unen una relación más directa con el medio y una mayor cercanía e interacción con personas, clientes y otros usuarios/as de la vía. En los casos en los que los desplazamientos se hacían a pie, como en la cartería y en la limpieza pública, se argumenta una mayor facilidad y comodidad en los desplazamientos, así como la posibilidad de cubrir un recorrido mayor, lo que implica en algunos casos también un incremento proporcional en la carga de trabajo no falto de conflictos: como nos relata un operario de limpieza "ahora los jefes obligan a moverte más". También destaca un cierto mayor respeto que se impone en la circulación, por tratarse de "profesionales" (sobre todo en los ejemplos más formalizados) y a la vez 
un trato más familiar y cercano, por la imagen de informalidad de la bicicleta, no exento de cierto paternalismo condescendiente, como ocurre en el caso de los bici-mensajeros: para los nuevos clientes, sobre todo para los no familiarizados con esta modalidad, siguen teniendo la imagen de amateurismo, provisionalidad y cierta indolencia juvenil, todo ellos enmarcado en una imagen de apariencia desaliñada y desaseada. Aquí el sudor, frontera que marca simbólicamente la diferencia entre lo manual y lo intelectual, es también criterio de minusvaloración.

En general, este carácter incorporado también implica unas mayores exigencias de rendimiento físico y de destreza técnica, a la par de una mayor exposición a la contaminación, a la lucha contra el tráfico y a las variaciones de la climatología. Todo ello exige un despliegue de cultura física, de técnicas, un manejo óptimo de la indumentaria, pero también una cierta relación de cercanía e implicación con el transporte en bicicleta. En otras palabras, estos oficios demandan cierta "cultura ciclista" previa, lo cual explica tanto los discursos de defensa a ultranza de la bicicleta que observamos entre algunos bicimensajeros, como el hecho de que la modalidad ciclista de algunas de estas profesiones (como la de policía local) se introduzca en muchos casos como opción voluntaria.

Junto a la diversificación y recorporeización de estos "nuevos oficios" nos encontramos con la introducción de la bicicleta en los desplazamientos cotidianos. Los testimonios de los ciclistas apuntan a una relajación emocional en los trayectos en bicicleta que suponen desplazamientos "obligados", dentro del tiempo de trabajo, estudio, etc. Nuevamente, los afectos canalizan la experiencia corporeizada, dotándola de sentido. Se trata en este caso de posibilidades de "escapada" de la rutina que proporciona la bicicleta en contraste con los medios de transporte motorizados, remarcando la experiencia del transporte como algo placentero, y que se traducen en cambios de recorrido o velocidad, rodeos, paradas o simplemente una atención improvisada a lo que ocurre en el entorno: pararse a hablar con alguien brevemente, ver un escaparate, etc. Cierta ruptura, en suma, de la racionalidad y el esquematismo de la vida diaria. Se discute así el razonamiento kantiano por el cual el deber, si es agradable, no puede ser tal deber, en la medida en que, como apuntan Elías y Dunning, el trabajo se configure como "una antítesis innata del placer" (1992: 87). En este sentido, este tipo de prácticas plantean una respuesta a la rutinización de la vida cotidiana que se instituye en el control social y personal de los afectos, pues la rutina "entra en juego en todas las situaciones en que los individuos han de subordinar sus sentimientos e impulsos momentáneos a las demandas que, directa o indirectamente, les impone su posición social" (1992: 95). Así, dar un rodeo para llegar al trabajo, por ejemplo, supone el placer de "escaparse", salirse del guion, situarse en un nuevo escenario en el que se procura cierto disfrute personal.

El uso de la bicicleta procura así un cierto descontrol emocional en una sociedad que ejerce un significativo control del despliegue de las emociones en público. Un descontrol eso sí, moderado y discreto, acercándose a la expresión corporeizada del placer de pedalear, de enunciar públicamente el movimiento físico, la respiración, la sudoración, etc. Supone no solo proyectarse, abrirse y mostrarse a los demás, sino dirigirse hacia uno mismo, en cierto ejercicio de introyección. Las connotaciones de este "descontrol emocional", que no es más que expresión de las emociones sentidas (o si se quiere, descontrol de las restricciones corporales) implican no solo desconexión sino también catarsis. Así, comprobamos como el uso de la bicicleta en la ciudad también permite, sobre todo entre los más jóvenes y más expertos técnicamente, encontrar una oportunidad para descargar la adrenalina, esta vez bajo la lógica de la emoción a través de la tensión, más que de la relajación. Es el caso de ciclistas que nos hablan de "preferir circular entre el tráfico que por el carril bici", no solo porque se quiera llegar antes, sino porque se quiera experimentar la activación física, la medición con el tráfico... en suma, el placer a través de la experimentación con el riesgo y la velocidad. 
Por otra parte, la experiencia ciclista corporeizada, cuando tiende a cargar las implicaciones del desplazamiento hacia una actividad obligada, lo que ha llevado tradicionalmente a caracterizar a este tipo de desplazamientos como "utilitarios" (Pucher y Buhler, 2012) u "obligados" (por estar sujeto a horario, destino, etc.) de una serie de connotaciones de sentido que suponen descargas de control emocional, liberación del cuerpo y de los afectos. Pero las posibles rigideces en la separación conceptual entre desplazamientos "obligados" y "no obligados" podrían dejar en un espacio de indefinición, por ejemplo, aquellos trayectos que se dirigen a actividades en las cuales están presentes restricciones en términos de horario, destino o función, pero formarían parte del ocio (trámites administrativos, compras, citas por compromiso, etc.). Idéntico razonamiento podría aplicarse a aquellos usos "deportivos" que pueden estar racionalizados y medidos, rígidamente afectados por horario, destino o función. Piénsese en las salidas organizadas para el entrenamiento ciclista, por ejemplo, en las que el plan de entrenamiento (más o menos explícito, según el nivel de exigencia) obliga a un determinado guión preestablecido, de manera que los recorridos suelen están prefijados de antemano, al igual que el kilometraje, la intensidad, la compañía, por no hablar de otras variables predecibles con los nuevos aparatos de medición e información, como la climatología, las calorías gastadas, el desnivel cubierto o los vatios de potencia empleados. Este tipo de lagunas, contradicciones y espacios de indefinición llevan a la necesidad, como advierte Cox (2005:23), no solo de abordar una más compleja diferenciación del ocio entre "juego" y "tiempo libre organizado", sino a la necesidad de revisar profundamente las nociones comúnmente aplicadas a la diferenciación de los usos ciclistas, como las relativas a la utilidad, el ocio y el deporte. ${ }^{2}$ Incluso el tiempo libre, podríamos añadir, siguiendo (Baudrillard, 2009: 189), implica tener tiempo pero tal tiempo, pasado por el tamiz de la posesión deja de ser tal "tiempo libre". El tiempo que se pierde se convierte en tiempo que se consume, máxima que se confirma tanto más cuanto, como vemos, se confunden las lógicas que gobiernan tiempo de ocio y tiempo de trabajo. Otros autores llevan a radicalizar esta opción: lo que es realmente "obligado" en nuestra sociedad en términos de movilidad es el uso del automóvil, pues culturalmente todo a ello conduce: modelos de movilidad, diseños de las ciudades, patrones de consumo, idearios de prestigio e identidad (Urry, 2004). Claro que esto podría llevar a adscribirse directamente al idealismo que considera a todos los ciclistas sin excepciones como personas que sonríen en sus agradables paseos de ocio o de negocio, excluyendo así a todos aquellos que pedalean por necesidad porque no pueden permitirse un coche, y que realmente sueñan con tenerlo.

\section{Cuerpos contestatarios: entre la salud individual y la salud colectiva}

El tercer y último estereotipo dominante con respecto a la población ciclista, marcado como el resto por un fuerte componente estético, con su propia imagen hermética atribuida, es el del ciclista concienciado y comprometido con el medio ambiente, lo que lleva atribuciones de una determinada imagen, asociada o no a categorizaciones simplificadoras (del tipo "hippies", "ecologistas", "de izquierdas", etc.) o a etiquetajes despectivos ("perroflauta", "biciflauta", etc.). La correspondencia esperada entre un pensamiento y una estética es común en tales atribuciones: el que usa la bicicleta, normalmente identificado con alguien joven, debe ser "algo ecologista" o, al menos, debe mostrar una vestimenta desenfadada que lo corrobore. Con este tipo de "ataduras de la imagen" Goffman (1981: 90), se nos anuncia la dificultad de escapar del papel que en virtud a las expectativas sociales resulta atribuido, pues es la impresión involuntaria que damos la que nos delata. Desde el punto de vista de los afectos, escapar de los papeles socialmente generados origina tensiones emocionales:

2 Dentro de una "estructura más general de comprensión de las prácticas sociales" (Cox, 2015:24) este autor examina la interacción de tres elementos encontrados en cada práctica: competencias, significados y materiales, en un intento de explicación, que de este modo, tampoco escapa a la influencia de cierta taxonomía explicativa. 
los afectos se desubican con la transgresión de la norma estética socialmente impuesta y surgen la sorpresa, el escándalo o la conmoción, por una parte, y por la otra la vergüenza, el recato o el pudor.

Por fortuna, la reificación y naturalización de las identificaciones no son el único resultado y, en nuestras ciudades, es posible la resignificación y complejización de las atribuciones estéticas tanto por quienes las elaboran como por quienes son objeto de ellas, en una suerte de juego performativo que permite la "agencia" frente a la dictadura de la normalización. Algo, que, por ejemplo, ya se ha venido trabajando en el ámbito de las elaboraciones simplificadoras patriarcalistas y heterosexistas (Butler, 2007:99). Además, en nuestro trabajo de campo, encontramos que el mayor desarrollo ciclista en algunas ciudades andaluzas en los últimos años ha conllevado una mayor diversidad de perfiles estéticos y, en consecuencia, una cierta relativización de los estigmas fundamentados en esta diferencia de imagen pública. Aunque hay que tener en cuenta que la historia de esta diversidad es relativamente reciente. En el caso sevillano, por ejemplo, los informantes nos relatan que no hace más de 10 años, cuando ir en bicicleta era un signo mucho más contestatario de lo que es ahora, casi era obligación ir vestido de un modo que "explicase" por qué se optaba por hacer "esa cosa tan rara que se estaba haciendo": "ah, es deportista", "ah, es un hippie".

Pero, al margen de las atribuciones de imagen, la etiqueta "contestataria" cobra sentido en la medida en que podría plantear una posible tensión entre las preocupaciones sociales por una ciudad "más sana", libre de contaminación y ruidos, y las pretensiones de individuos que intentan cuidar de su propia salud en la ciudad. Explorar las contradicciones y tensiones dentro de este esquema entre "salud individual" y "salud colectiva" pasa en primer lugar por admitir la relevancia de aquellos estudios que insisten en armonizar dicha relación desde el punto de vista de las ciencias médicas (véase por ejemplo: Oja y otros, 2011. Götschi y otros, 2016. De Hartog y otros, 2010), a lo que se suma una opinión social muy favorable, complementada en el diseño de planes de acción política. En nuestro caso, por ejemplo, hemos encontrado cierta presencia de marcos de coordinación a escala autonómica bajo la asociación salud-bicicleta entre la Consejería de Igualdad, Salud y Políticas Sociales y la Consejería de Fomento y Vivienda hasta 2015, al margen de otras iniciativas a nivel local.

Pero la lectura de la salud individual a partir de la práctica ciclista no está exenta de contradicciones, que provienen del hecho de que la salud en nuestras sociedades, como refiere Baudrillard (2009: 170) "es menos un imperativo biológico vinculado con la supervivencia, que un imperativo social vinculado con el estatus". Una primera fuente de contradicciones proviene de un poder biomédico que ejerce su influencia tan sutil como poderosa. Desde la salud asistencial, por ejemplo, es cada vez más común que el ejercicio "se recete" desde las consultas médicas, como documentan muchos de nuestros informantes, apareciendo así ya la bicicleta dentro del posible catálogo de cambios de hábitos y reorientación hacia pautas de comportamiento "saludables". La actividad física se plantea como antídoto o como fármaco frente a la amenaza de enfermedades, a la par que la instauración de cierto miedo medicalizado impele al paciente a "moverse" por temor a la enfermedad, que es el miedo al dolor y a la muerte. Parece así comprensible que en nuestro trabajo de campo, por lo general, encontremos que este tipo de preocupaciones sobresalga entre quienes superan la barrera de los 45-50 años.

El argumento por el cual la actividad físico-deportiva, independientemente de su medida, es esencialmente saludable, se ha mantenido casi invariable hasta nuestros días, formando parte de los fundamentos del deporte moderno desde sus orígenes (Vigarello y Holt, 2005: 353), dentro de una lógica que instauraba también a la salud dentro de los avances de la modernidad hacia el progreso indefinido. La estrecha relación entre el cuidado del cuerpo a través del deporte y las pautas de consumo (Featherstone, 2010: 200) complementa esta tendencia social a través de una maquinaria mercantil que respalda la idea del cuidado del cuerpo como ideal cultural estético-productivista. En los discursos recabados destacan tan- 
to el seguimiento acrítico de esta tendencia como aquellos casos, los menos, que plantean cierto tipo de reacción:

“A nivel deportivo está este tipo de nazismo que se ha instalado desde hace unos diez años que es el no fumar, el comer sano, el llevar una vida adecuada digamos... Y eso ha hecho que haya supermercados del deporte que están saliendo como hongos. Fíjate en las publicidades que hay... y eso te llega. La gente se tiene que decidir por un deporte y mucha gente empieza corriendo y ve que después le duelen las rodillas y empieza con la bicicleta...". (Empresario de la bicicleta, Sevilla).

Cuando los médicos "mandan" bicicletas vinculan los individuos a un deporte que, pese a su carácter socialmente indiscutido, también comporta excesos, consumos desmedidos y problemas para la salud. Con estas prácticas físico-deportivas parece decantarse la balanza desde un enfoque físico-orgánico hacia los beneficios por encima de los perjuicios, pero también tales prácticas buscan amparo en la competitividad, la vanidad, los narcisismos y, en general, las carencias de sentido de una sociedad que sitúa a su cuerpo provisorio en el centro de su existencia. Un cuerpo sobredimensionado convertido en "categoría de especie y categoría de identidad" Velasco, 2010: 21), pero a la vez crecientemente diluido por la expansión técnico-científica que desdibuja las fronteras entre lo biológico y lo tecnológico, entre lo natural y lo artificial (Martin, 1990: 121).

Encontramos que, en los relatos sobre la relación entre especialistas médicos y pacientes, se produce una suerte de incursión selectiva por los primeros en el modo de vida de los segundos, las propuestas de cambio de hábitos y comportamientos selectivos se yuxtapone con una significativa menor presencia de recomendaciones hacia otros escenarios que puedan explicar el deterioro en la salud, tales como: la precariedad en las condiciones de trabajo y la presión sufrida dentro de este, la calidad de las relaciones familiares y sociales o la propia manera de enfocar la vida anímica, social y afectivamente. No en vano, el personal sanitario también es parte de una sociedad que entiende que corporeizar los problemas es cosificarlos y pasarlos por el tamiz estético-productivista, en lugar de afrontarlos. Es una sociedad que piensa que las soluciones principales a tales problemas pasan en buena parte por cambiar la apariencia corporal, por lo general modelada técnicamente, y por eso también pueden mirar al mismo lado que, por ejemplo, una persona en paro que se apunta al gimnasio para adormecer con endorfinas su frustración. "Recetar bicicletas", promocionar el ejercicio ciclista desde la salud es una buena medida para procurar ciudadanos sanos, pero también implica el riesgo de pensar que en el cuerpo se agota la intervención, la posibilidad de cambio, porque se entiende que el límite del individuo está en su cuerpo y que las soluciones a los problemas de salud se centran en la reinvención técnica de este (Jordi, 2016a: 236). Pero decir reinvención técnica es poco: desde Descartes sabemos que la transformación corporal es una redefinición en los límites que nos relacionan con el mundo.

Por otra parte, desde el punto de vista de la salud colectiva, la tensión entre salud individual y salud colectiva nos lleva a reflexionar sobre unas ciudades en las que, desde la promoción ciclista, se "arroja" a pedalear a miles de individuos como "stakhanovistas" de la salud colectiva, en su lucha contra el riesgo y la contaminación, sacrificando en cierta medida la salud del individuo para salvar la salud de la ciudad. Desde que se asume en la literatura científica que dicha relación no es problemática (véase por ejemplo: Oja et al, 2011), asegurándose que los beneficios de pedalear para la ciudad son superiores a los costes de salud para los individuos, el problema parece resuelto. Pero las vivencias de los individuos no siempre van en la misma dirección. Dos escenarios de contestación destacan aquí en el escenario analizado: 
- aquellos que se desenvuelven en espacios en los cuales las infraestructuras son débiles y la lucha contra los rigores del tráfico y la contaminación se hace más evidente

- aquellos que sufren los avatares de dicha lucha de forma constante y cotidiana ya que, por su trabajo, conviven a diario con el tráfico rodado en la calzada, como es el caso de los bicimensajeros:

"Es asqueroso. Veo la parte de atrás de los autobuses negra. Cuando arrancan sueltan una humareda... (...) Y tú que tienes que arrancar y tienes los pulmones más abiertos porque estás haciendo ejercicio, es que te lo llevas..."

Parece evidente que sin mejores infraestructuras ciclistas y, sobre todo, sin mayores medidas de control del tráfico rodado en las ciudades, el aumento del tráfico ciclista puede convertirse, paradójicamente en otro problema de salud. Sin embargo, allí donde las infraestructuras ciclistas en Andalucía han avanzado más en calidad y en cantidad, los interrogantes y los retos no acaban, sino que se inicia un nuevo proceso de repercusiones aún más complejas. En una ciudad como Sevilla, inundada con más de 160 kilómetros de verdes carriles-bici, los interrogantes pasan por la necesidad de superar la "muerte de éxito" que supondría, como se refiere desde el movimiento pro-bici ${ }^{3}$ en pensar que ha alcanzado su "techo" en la promoción ciclista después de haber llegado a ser un referente a nivel mundial (Marqués y otros, 2015). Algunos colectivos de activistas consultados subrayan así el peligro de haber alcanzado un status quo en la ciudad que aleja el conflicto y así un mayor grado de transformación de la movilidad en la ciudad, llegando a un punto de saturación. Aunque de forma minoritaria, desde otros entornos del movimiento asociativo andaluz se ha venido haciendo campaña en contra de este tipo de intervención, planteando cierta resistencia a una implantación generalizada del carril-bici, y optando por un modelo combinado de limitación del tráfico motorizado y de fortalecimiento de las capacidades del ciclista, compartiendo todos los vehículos un mismo espacio (Del Río y Coca, 2016: 58). Desde ambos enfoques la conclusión de este proceso podría ser parecida: de forma sincrónica a la presencia creciente de carriles-bici, de forma tan rápida y efectiva, la hegemonía del tráfico motorizado habría dado "otro paso más", posibilitando "pintar de verde" una realidad que seguiría invariante, esta vez con un colectivo ciclista en buena parte desactivado ya que su conquista fundamental, el carril-bici, se habría ya alcanzado. Paradójicamente, no sería así la ciudad la que evidenciaría su resiliencia socioecológica ante el cambio climático, sino el sistema contaminante y el transporte motorizado desde su hegemonía el que habría planteado, en su nueva "mutación verde", un comportamiento resiliente al absorber a las propuestas ambientalistas.

En este sentido, si bien el interés por la infraestructura ha ocupado un lugar central en las últimas políticas de promoción de la bicicleta en Andalucía, y existe una percepción extendida dentro del movimiento pro-bici de que ni siquiera la continuidad de este en términos de apoyo continuado por las administraciones parece garantizada (Del Río y Coca, 2016: 59-60), ni los colectivos ciclistas parecen desactivados ni el proceso puede encontrarse, necesariamente, en una permanente fase de letargo. Más bien podemos hablar de que el colectivo pro-bici parece experimentar un proceso de diversificación y complejización que da cuenta de su evolución ante los nuevos acontecimientos, conviviendo dos vertientes paralelas, como documentan Del Campo y Gálvez (2016: 141):

\footnotetext{
3 La denuncia desde algunos colectivos ciclistas sevillanos del abandono de las labores de promoción ciclista es un claro ejemplo. Es el caso, por ejemplo, de las reacciones ante la desaparición de la Oficina de la Bicicleta, entidad centralizadora de los impulsos de promoción ciclista en la ciudad, o ante el descenso del cuarto al décimo lugar en el ranking elaborado por la consultora Copenhagenize: http://www.eldiario.es/andalucia/sevilla/ bicicleta-carril_bici-Sevilla-Copenhague_0_394411768.html.
} 
- De un lado, los vínculos asociativos más consolidados y veteranos en la lucha pro-bici, de gran repercusión política, legal y hacia el exterior, cuyos portavoces suelen ser varones que superan ampliamente los 40 años, ligados al activismo ecologista y de izquierdas y cuyas reivindicaciones centrales han giro en torno a la expansión del carril bici como infraestructura fundamental.

- De otro lado, los vínculos más efímeros, flexibles y actuales, que se centran más en acciones concretas y locales, que se especializan en el trabajo a partir de redes sociales, y están liderados por personas menores de 40 años, con una ideología y posicionamiento político mucho más difusos y heterogéneos y con un posicionamiento más flexible con respecto al carril- bici.

Se produce una especie de "relevo generacional", con planteamientos más postmodernos, flexibles e híbridos pero es relevante el modo en que tales diferencias no son absolutas, y el peso de las confluencias sigue siendo determinante, alejándose, al menos de momento, la posibilidad de una esclerotización del movimiento pro-bici en Andalucía. En todo caso, el desafío de este movimiento es mantener un estado de alianzas pragmáticas dirigidos a planteamientos de largo plazo, buscando fortaleza en la diversidad, más que debilidad, por lo parece comprensible, como que "en consonancia con otros movimientos sociales, no deberíamos sorprendernos de encontrar (en este movimiento) tanto modos reformistas como revolucionarios de la actividad y del activismo" (Cox, 2015: 35-36).

\section{Reflexiones finales: ¿pedalear hacia donde?}

Las contradicciones de los usos y prácticas ciclistas reflejan en buena parte las fallas y tensiones de nuestra propia sociedad, relativa a las concepciones sobre el cuerpo, la salud, el ejercicio físico o la lucha por el medio ambiente. El conocimiento de algunas de estas fallas y tensiones tal vez sirva para consolidar prácticas y políticas no ilusorias, conectadas con expectativas sociales reales, alejándose de un estéril idealismo. Ello no implica despreciar ni la imaginación ni las utopías creativas, fundamentales para pensar un futuro alternativo a la hegemonía depredadora del vehículo privado, pero tales alternativas planteadas a los sistemas de movilidad dominantes pasan por un conocimiento profundo de las limitaciones y contradicciones del pedalear como un ejercicio social, complejo y cambiante, sujeto a reconstrucciones y resignificaciones por los agentes sociales.

Del análisis de los estereotipos y afectos ciclistas se concluye que la bicicleta no es para todos. El origen de su universalidad proviene de los relatos un tanto idealizadores que propagan sus beneficios, que cobran mayor sentido en contraposición con el coche, contra el cual la bicicleta se sitúa como un vehículo indiscutiblemente menos incluyente, al no presentar tantas restricciones de renta, edad o trámites administrativos. Sin embargo, la bicicleta presenta exclusiones que tienen un alto grado de corporeización, relativas a la destreza técnica, a la asunción del riesgo, a las capacidades físicas, a la situación en términos de salud, entre otras, sometidos todos a percepciones valorativas por parte de los usuarios que lo condicionan como elementos relevantes. Esto no conlleva negar el poderoso potencial de revitalización de los sentidos y de los afectos de la bicicleta en unas ciudades dominadas en términos materiales y simbólicos por el tráfico motorizado.

En todo caso, la creciente diversificación ciclista en algunos espacios deviene en una mayor normalización, y esta se impone tanto en la yuxtaposición de usos físico-deportivos y de transporte, como en la diversificación creciente de usos productivos, oficios recorporeizados con base en la bicicleta. Todo ello coadyuva en una mayor democratización de la práctica ciclista, contra la persistencia de los agentes sociales que se afanan en ubicar barreras simbólicas en la apariencia corporal, basada o no en prejuicios de clase para la producción de estereotipos. 
Por otra parte, comprobamos que el idealismo convive con la estereotipia. La primacía del cuerpo atlético, como hemos visto, combinada con la persistencia de los estereotipos, significa que las implicaciones liberadoras del uso de la bicicleta (en términos de movilidad, coste, mejora de la salud, o de una mayor exploración de los sentidos) se entrecruzan con una práctica deportiva con fines de transformación corporal que comporta inevitables ataduras estéticas, y posibles imposiciones y controles, como el entrenamiento rutinario o la medicalización de los hábitos de salud. Las tensiones entre salud individual y colectiva revelan la importancia de entender en términos fenomenológicos las complejas experiencias y vivencias sobre la salud, más allá de simplificaciones.

Finalmente, advertir de los enormes desafíos de la bicicleta en una ciudad pensada por y para el coche, no puede conducir a homogeneizar ni a simplificar una cosificada "cultura ciclista", libre de tensiones, idealizada y prístina. Más bien debería llevar a advertir sus efectos indudables en el mantenimiento de una cultura ciclista dominante que busca la perpetuación a través de la mutación en continuas subculturas, buena parte de ellas concretadas en alternativas de consumo estereotipadas, como la reciente tendencia "fixie". Es decir, entendemos que el desarrollo de tales "subculturas de la bicicleta" es a la vez un síntoma y un obstáculo más para la ansiada democratización o normalización ciclista. Las estrategias de promoción afrontan el reto de tal democratización, pero si por esta se entiende homogeneización, la bicicleta puede terminar siendo víctima de sí misma. Si se entiende como explosión de la diversidad, los retos a asumir serán más complejos, en tanto implican asumir las fracturas y fallas que la sociedad impone al devenir del futuro ciclista en nuestras ciudades, que pasan por las exclusiones de partida que impone la sociedad. En definitiva, implica asumir la posible absorción del proceso de promoción por parte de las modas que generan tendencias de consumo, entendiendo como refieren Horton y Parkin (2012: 314) que la reversión de los sistemas de movilidad actuales requieren más bien de una auténtica "revolución" y por tanto, "no se trata de consolidar una moda o tendencia, sino de aprovechar la moda para hacer el ciclismo más popular". Y finalmente, supone asumir que la práctica del ciclismo urbano, además de una respuesta frontal a un modelo de ciudad y de ambiente insostenible, alberga implicaciones no siempre liberadoras ni emancipadoras, pues dependen del contexto sociopolítico y económico en el que se desarrollen, de las imágenes y afectos asociados y del rumbo de los complejos procesos de cambio que lleva incorporados. Así, en el marco descrito, con fines más estimulantes del conocimiento de esta complejidad, más que desalentadores, deberíamos preguntarnos, ¿supone la presencia creciente y notoria de la bicicleta una transformación radical de los afectos en la ciudad y una reversión del modelo de producción-consumo depredador del medio o más bien una revolución de la estética de la ciudad, que se hace cada vez más "verde" pero a la vez implica el riesgo de un nuevo enroque en el reinado del automóvil?

\section{Agradecimientos}

Este artículo es en gran parte producto del trabajo colectivo desarrollado bajo el Proyecto CICLA (Movilidad Sostenible en Andalucía: prácticas y discursos en el uso de la bicicleta), financiado por la Consejería de Fomento y Vivienda de la Junta de Andalucía, durante la convocatoria 2013-2014 de Proyectos de Investigación, Desarrollo e Innovación, y por tanto es deudor del apoyo de las entidades financiadoras y de las aportaciones de los integrantes del equipo investigador de dicho proyecto (ver: www.proyectocicla.org).

\section{Bibliografía}

ALDRED, Rachel; WOODCOCK, James y GOODMAN, Anna

2016 "Does More Cycling Mean More Diversity in Cycling?", en Transport Reviews. 36 (1): 28-44. 
AUGÉ, Marc

2009 Elogio de lo bicicleta. Barcelona: Gedisa.

BAUDRILLARD, Jean

2009 La sociedad de consumo: sus mitos, sus estructuras. Madrid: Siglo XXI. [Orig.1970]

BOLTANSKI, Luc

1971 "Les usages sociaux du corps", en Annales. Économies, Sociétés, Civilisations. 26, 1: 205233

BOURDIEU, Pierre

$1990 \quad$ Sociología y cultura. México: Grijalbo.

BUTLER, J.

2001 El género en disputa. México: Paidós.

CAILLAT, Michel

1999 "Le sport, capitaliste par essence" http://1libertaire.free.fr/MCaillat06.html. (11-04-2016).

CLOUGH, Patricia Tiniceto

2008 "The affective turn. Political economy, biomedia and bodies", en Theory, Culture and Society, 25: 1-2.

COX, Peter (Edit.)

2015 Cycling cultures. Chester: University of Chester.

DEKOSTER, J. y SCHOLLAERT, U.

1999 "Cycling: the way ahead for towns and cities", en European Commision. http://ec.europa. eu/environment/archives/cycling/cycling_en.pdf (11-04-2016).

DEL CAMPO, Alberto y GÁLVEZ, Cristina

2016 "Interacciones, sociabilidades y asociacionismo ciclistas", en Hernández, M. (Comp.). Bicitopías. Hacia una antropología de la movilidad urbana: 117-143. Barcelona: Icaria.

DEL RÍO, Ángel y COCA, Agustín

2016 "El Plan Andaluz de la Bicicleta y los foros de participación”, en Hernández, M. (Comp.). Bicitopías. Hacia una antropología de la movilidad urbana: 53-70. Barcelona: Icaria.

DE HARTOG, Jeroen Johan; BOOGAARD, Hanna; NIJLAND, Hans y HOEK, Gerard

2010 "Do the health benefits of cycling outweigh the risks?", en Environmental health perspectives, 118, 8: 1109-1116.

DOUGLAS, Mary

1978 Símbolos naturales: exploraciones en cosmología. Madrid: Alianza. [Traduc. Carmen Criado]

FEATHERSTONE, Mike

2010 "Body, image and affect in consumer culture", en Body \& Society, 16(1): 193-221.

GELDER, Ken

2007 Subcultures: Cultural histories and social practice. Nueva York: Routledge.

GÖTSCHI, Thomas; GARRARD, Jan y GILES-CORTI, Billie

2016 "Cycling as a part of daily life: A review of health perspectives", en Transport Reviews, 36(1): 45-71.

HORTON, Dave

2006 "Environmentalism and the Bicycle", en Environmental Politics, 15(1): 41-58.

2012 "Fear of Cycling", en Horton, D.; Cox, P. y Rosen, P. (Edits.). Cycling and Society. Hampshire: Ashgate.

HORTON, Dave y PARKIN, John

2012 "Conclusion: Toward a revolution in Cycling", en Parkin, J. (Edit.) Transport and Sustainability. Volume 1: Cycling and Sustainability: 303-325.Bradford: Emerald Insight.

HORTON, Dave y JONES, Tim

2015 "Rhetoric and Reality: Understanding the English Cycling Situation", en Cox, Peter (Ed.)

ILICH, Ivan Cycling cultures: 203-213. Chester: University of Chester.

1985 La convivencialidad. Madrid: J.Mortiz, Planeta.

JACOBS, Jane

2011 Muerte y vida de las grandes ciudades. Madrid: Capitán Swing 
KRABBÉ, Tim

2010 El ciclista. Barcelona: Los libros del lince.

JORDI, Mario

2014 "El músculo negado. Placer artesano y relaciones socio-afectivas en el culturismo femenino", en Gazeta de Antropología, 30, 3.

2016 a "Bicicleta y corporalidades", en Hernández, M. (Comp.). Bicitopías. Hacia una antropología de la movilidad urbana: 209-239. Barcelona: Icaria.

2016 b "Bicicleta, deporte y naturaleza", en Hernández, M. (Comp.). Bicitopías. Hacia una anLEYS, Ruth tropología de la movilidad urbana: 181-206. Barcelona: Icaria.

2011 "The turn to affect: A critique", en Critical Inquiry, 37(3): 434-472.

LIPOVETSKY, Gilles

$2000 \quad$ La era del vacío. Barcelona: Anagrama.

LUHMANN, Niklas (1998) Sistemas sociales. Barcelona: Anthropos.

MAFFESOLI, Michel

2004 El nomadismo: vagabundeos iniciáticos. México: Fondo de Cultura económica.

2007 En el crisol de las apariencias: para una ética de la estética. Madrid: Siglo XXI.

MARQUÉS, Ricardo; HERNANDEZ-HERRADOR, Vicente; CALVO-SALAZAR, Manuel y GARCÍA-CEBRIAN José Antonio

2015 "How infrastructure can promote cycling in cities: Lessons from Seville", en Research in Transportation Economics, 53: 31-44.

MARTIN, Emily

1992 "The end of the body?", en American Ethnologist, 19(1): 121-140.

MARTÍN, Isabel y GÁLVEZ, Cristina

2016 "De éxitos y fracasos: discursos sobre infraestructuras ciclistas", en Hernández, M. (Comp.). Bicitopías. Hacia una antropología de la movilidad urbana: 31-50. Barcelona: Icaria.

MASSUMI, Brian

2002 Parables for the Virtual. Durham: Duke University Press.

MORALES, Luis

2010 "Movilidad en bicicleta y resiliencia socioecológica: el caso de la ciudad de Sevilla", en CONAMA-10. Congreso Nacional del Medio Ambiente. http://www.conama10.conama. org/conama10/download/files/CT\%202010/40885.pdf (11-04-2016)

OJA, P.; TITZE, S.; BAUMAN, A.; DE GEUS, B.; KRENN, P.; REGER-NASH, B. y KOHLBERGER, T.

2011 "Health benefits of cycling: a systematic review", en Scandinavian Journal of Medicine \& Science in Sports, 21(4): 496-509.

PUCHER John y BUEHLER, Ralph. (Edits.)

$2012 \quad$ City Cycling. Cambridge: MIT Press.

SIMMEL, Georg

1969 "Sociology of the senses: Visual interaction", en Park, R. E. y Burgess, E. W. Introduction to the Science of Sociology. Chicago: University of Chicago Press. [Orig.1921]

SPINNEY, Justin

2012 "Cycling the city: non-place and the sensory construction of meaning in a mobile practice”, en Horton, D., Cox, P. y Rosen, P. (Edits.). Cycling and society: 25-45. Hampshire:

URRY, John Ashgate Publishing, Ltd.

2004 "The 'system'of automobility", en Theory, Culture \& Society, 21: 4-5.

VIGARELLO, George y HOLT, Richard

2005 "El cuerpo cultivado: gimnastas y deportistas en el siglo XIX", en Courtine, J. J., Corbin, A., y Vigarello, G. Historia del cuerpo, 2: 295-354. Madrid: Taurus. 